\title{
Quality of Life Parameters should be Included in the Preoperative Informed Consent in Patients with Chronic Rhinosinusitis Scheduled for Functional Endoscopic Sinus Surgery
}

\author{
Petros V. Vlastarakos ${ }^{10}$ Nikolaos S. Tsilis ${ }^{2}$ Thomas P. Nikolopoulos ${ }^{2}$ Pavlos Maragoudakis ${ }^{2}$
}

${ }^{1}$ Department of ENT, MITERA Paediatric Infirmary, Athens, Greece 2 Department of ENT, Attikon University Hospital, Athens, Greece

Int Arch Otorhinolaryngol 2019;23:250-252.

Dear Editors,

Functional endoscopic sinus surgery (FESS) is effective in patients with chronic rhinosinusitis who have failed medical treatment. ${ }^{1}$ Indeed, these patients bear a significant disease burden, as the nasal congestion, the purulent nasal discharge, the postnasal drainage, and the recurring headache inevitably affect their physical and emotional well-being and, thus, their quality of life (QoL). ${ }^{2}$

However, in addition to the medical effectiveness of FESSmeasured in terms of improved symptom control, or lack of work absenteeism as undisputed measures of treatment success-QoL has been increasingly recognized as an important outcome parameter for patients. ${ }^{2}$ Hence, in addition to the expected clinical effectiveness of FESS, an appropriate preoperative informed consent requires that the patient be aware of the effect of the proposed intervention on his/her QoL.

In a prospective study conducted at a tertiary university hospital, 84 patients filled in the Glasgow Benefit Inventory $(\mathrm{GBI}){ }^{3}$ a validated questionnaire focusing on QoL after a surgical intervention, 1 year after a FESS operation for chronic rhinosinusitis (without nasal polyps). The GBI consists of three domains, which assess a patient's perception on the success of a certain operation regarding the general benefit, physical health status, and social support, respectively. The study sample comprised 49 men and 35 women, with a mean age of 45.4 years (standard deviation [SD] $= \pm 14.2$ ).

-Table 1 shows the descriptive statistics for the GBI subscales. The median value for the general benefit subscale was 33.33 (interquartile range [IQR]: 18.75-52.08), for the physical health status 16.67 (IQR: $0.00-50.00$ ), for social support 0.00 (IQR: $0.00-16.67$ ), and for the overall (total)

(1D) Petros V. Vlastarakos's ORCID is https://orcid.org/0000-00022803-1971.

received

March 4, 2018

accepted

October 21, 2018

published online

February 15, 2019
Address for correspondence Petros V. Vlastarakos, MD, MSc, PhD, IDO-HNS (Eng.), Department of ENT, MITERA Paediatric Infirmary, 6 Erythrou Stavrou Str., Marousi-Athens 15123, Greece (e-mail: pevlast@hotmail.com; pevlast@yahoo.gr).

QoL 27.78 (IQR: 19.44-44.44). In addition, the respective proportion of patients who perceived benefit from the operation was $92.9 \%$ for the general subscale, $56 \%$ for the physical health status, $41.7 \%$ for social support, and $94 \%$ for the overall QoL (-Fig. 1). A comparison of the GBI scores between men and women, by employing the non-parametric Mann-Whitney test, did not reveal significant differences, either regarding the respective subscales, or the overall QoL $(p>0.05)$. Correlation analysis of the GBI subscales with age showed negative, and low correlation between the patients' age and their general benefit score (Spearman $r=-0.22$, $p=0.042$ ).

Hence, the use of the GBI in the present study allowed quantitative assessment of an otherwise subjective parameter, such as the postoperative QoL after FESS. Thus, not only FESS has a positive impact on the health status of chronic rhinosinusitis patients, but it is also beneficial for their overall QoL.

Table 1 Postoperative patient score according to the Glasgow Benefit Inventory subscales

\begin{tabular}{|l|l|l|l|l|}
\hline & Minimum & Maximum & $\begin{array}{l}\text { Mean } \\
\text { (SD) }\end{array}$ & $\begin{array}{l}\text { Median } \\
\text { (IQR) }\end{array}$ \\
\hline $\begin{array}{l}\text { Total } \\
\text { score }\end{array}$ & -16.67 & 58.33 & $\begin{array}{l}28.11 \\
(18.26)\end{array}$ & $\begin{array}{l}27.78 \\
(19.44-44.44)\end{array}$ \\
\hline $\begin{array}{l}\text { General } \\
\text { subscale }\end{array}$ & -29.17 & 75.00 & $\begin{array}{l}32.94 \\
(23.59)\end{array}$ & $\begin{array}{l}33.33 \\
(18.75-52.08)\end{array}$ \\
\hline $\begin{array}{l}\text { Social } \\
\text { support }\end{array}$ & 0.00 & 66.67 & $\begin{array}{l}13.10 \\
(18.49)\end{array}$ & $\begin{array}{l}0.00 \\
(0.00-16.67)\end{array}$ \\
\hline $\begin{array}{l}\text { Physical } \\
\text { health }\end{array}$ & -16.67 & 100.00 & $\begin{array}{l}23.81 \\
(30.09)\end{array}$ & $\begin{array}{l}16.67 \\
(0.00-50.00)\end{array}$ \\
\hline
\end{tabular}

Abbreviations: IQR, interquartile range; SD, standard deviation.

Copyright @ 2019 by Thieme Revinter Publicações Ltda, Rio de Janeiro, Brazil
DOI https://doi.org/ 10.1055/s-0038-1676313. ISSN $1809-9777$.
License terms

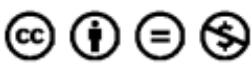




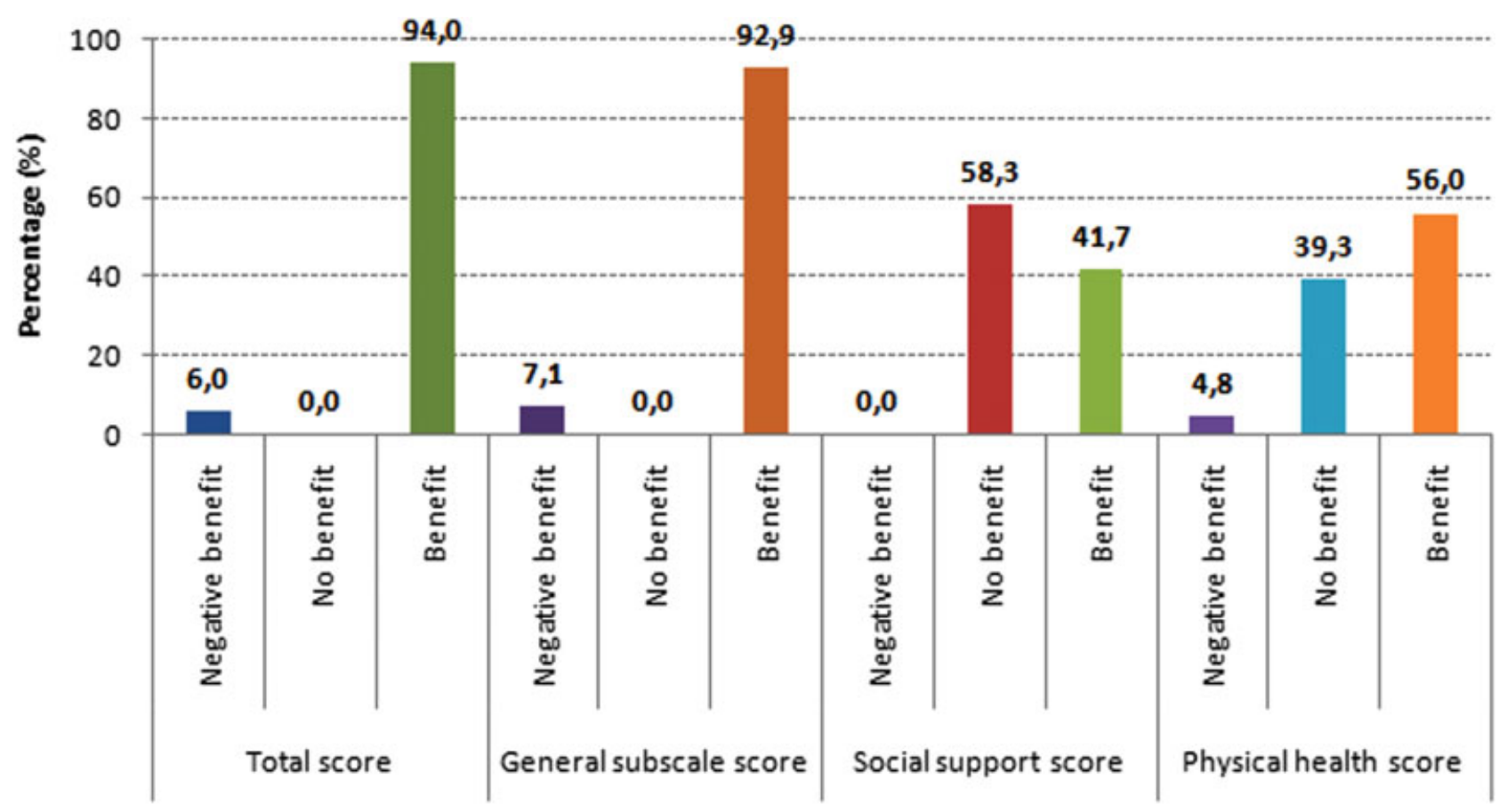

Fig. 1 Proportion of patients with negative benefit, no benefit and post-functional endoscopic sinus surgery benefit according to the Glasgow Benefit Inventory subscales.

This outcome is extremely important for medical ethics, as the process of obtaining preoperative consent presupposes that this consent is informed. Quality of life considerations can be taken into account during treatment planning and become part of preoperative counselling in patients undergoing FESS for chronic rhinosinusitis, to provide realistic patient expectations. Patients with chronic rhinosinusitis are likely to experience improvements in their QoL after FESS, irrespective of their gender. This improvement may be more limited in older patients. Issues pertaining social support are not likely to be postoperatively affected, probably because their leverage in the everyday life of chronic rhinosinusitis patients is limited.

\section{Ethical Approval}

All procedures performed were in accordance with the ethical standards of the institutional and national research committee and with the 1964 Helsinki declaration and its later amendments.
Funding

The authors have no financial interest and have not received any financial support for this article.

Author contribution

Drs. Vlastarakos and Tsilis equally contributed to the preparation of the manuscript.

Conflicts of Interest

None declared.

\section{References}

1 Fokkens WJ, Lund VJ, Mullol J, et al. EPOS 2012: European position paper on rhinosinusitis and nasal polyps 2012. A summary for otorhinolaryngologists. Rhinology 2012;50(01):1-12

2 Salhab M, Matai V, Salam MA. The impact of functional endoscopic sinus surgery on health status. Rhinology 2004;42(02):98-102

3 Robinson K, Gatehouse S, Browning GG. Measuring patient benefit from otorhinolaryngological surgery and therapy. Ann Otol Rhinol Laryngol 1996;105(06):415-422 
